\title{
Longitudinal impact of clinical and socioenvironmental variables on oral health-related quality of life in adolescents
}

\section{Janice Simpson PAULA ${ }^{(a)}$ José Nilton da CRUZ ${ }^{(b)}$ Thiago Gentil RAMIRES(c) Edwin Moysés Marco ORTEGA(d) Fábio Luiz MIALHE(e)}

\footnotetext{
(a) Universidade Federal de Minas Gerais - UFMG, Faculty of Dentistry, Departament of Social and Preventive Dentistry, Belo Horizonte, Minas Gerais, Brazil.

(b) Universidade Federal do Mato Grosso UFMT, Departament of Statistics, Cuiabá, Mato Grosso, Brazil.

(c) Universidade Tecnológica Federal do Paraná - UTFPR, Departament of Mathematics, Apucarana, Paraná, Brazil.

(d) Universidade de São Paulo - USP, Luiz de Queiroz College of Agriculture, Department of Mathematics, Statistics and Chemistry, Piracicaba, São Paulo, Brazil.

(e) Universidade Estadual de Campinas - Unicamp, Piracicaba Dental School, Department of Community Dentistry, Piracicaba, São Paulo, Brazil.
}

Declaration of Interests: The authors certify that they have no commercial or associative interest that represents a conflict of interest in connection with the manuscript.

\section{Corresponding Author:}

Fábio Luiz Mialhe

E-mail: mialhe@unicamp.br

https://doi.org/10.1590/1807-3107BOR-2017.vol31.0070

Submitted: Dec 22, 2016

Accepted for publication: May 29, 2017

Last revision: June 07, 2017
Abstract: The aim of the present study was to investigate the impact of oral diseases, socioeconomic status, and family environmental factors on changes in the perception of oral health-related quality of life (OHRQoL) in adolescents. A prospective cohort study was conducted in Juiz de Fora, Minas Gerais, Brazil, with a sample of 286 twelve-year-old adolescents from public and private schools, selected by means of multistage random sampling. The adolescents were clinically examined for dental caries experience (number of decayed, missing, and filled teeth - DMFT index), presence of bleeding, and orthodontic treatment needs. They were asked to complete the Brazilian version of the Child Perceptions Questionnaire $\left(\mathrm{CPQ}_{11-14}\right)$. In addition, parents answered a questionnaire about their socioeconomic status and family environmental characteristics. After 3 years, the adolescents were contacted again to participate in the research. Logistic regression models, with explanatory variables assessed both individually and jointly, were used to determine which independent variables impacted longitudinally on OHRQoL. The final result demonstrated that only DMFT explained part of the response variability in $\mathrm{CPQ}_{11-14}$ scores. In conclusion, caries experience was an important predictor of OHRQoL in adolescents followed up for 3 years.

Keywords: Quality of Life; Oral Health; Adolescent; Cohort Studies.

\section{Introduction}

Current dental research has shown the role of oral health status in quality of life, conceptualized as a multidimensional field that includes functional limitations and well-being. ${ }^{1}$

Associations between oral diseases and oral health-related quality of life (OHRQoL) in children and adolescents have been described in several cross-sectional studies. ${ }^{2,3,4,5}$ Albeit very helpful in investigating the potential causes of a health condition, prospective cohort studies in this area are still scarce. ${ }^{6}$

In addition, social determinants of health such as socioeconomic status and family environmental characteristics have been linked to oral health in children and adolescents. ${ }^{78}$ Therefore, other studies ${ }^{9,10,11,12,13,14}$ have 
evaluated the association between these variables in conjunction with OHRQoL and found that factors such as economic aspects of family and educational level of parents can influence adolescents' subjective perceptions of health.

Specifically with regard to family environment, studies on associations between clinical status and oral health behaviors have found that family has a strong influence on children's and adolescents' knowledge about and attitudes towards oral hygiene. ${ }^{15,16,17}$ Moreover, evidence has shown that family environmental aspects are related to OHRQoL. 10,11,12,13

In a recent systematic review on the theme, Kumar et al. ${ }^{12}$ found that reaching a consensus over the results of studies into theimpact of parental socioeconomic status and family environmental characteristics on children's OHRQoL is not an easy task. This is due to differences in study population, parental characteristics, variables collected, methods and statistical tests used. Furthermore, those authors verified that most studies had a cross-sectional design (i.e., one time point), and there was a scarcity of evidence from longitudinal studies, which have the capacity to investigate causal inferences. In particular, there were few studies published evaluating jointly the impact of oral health, socioeconomic status, and family factors on children's and adolescents' OHRQoL over time. ${ }^{12,18,19,20,21}$

Therefore, the objective of this prospective cohort study was to investigate the impact of factors related to oral diseases, socioeconomic status, and family environmental on changes in OHRQoL of Brazilian adolescents.

\section{Methodology}

This study was approved by the Research Ethics Committee of the DentalSchool affiliated with University of Campinas, protocol number 147/2012. Parents signed a consent form allowing their children to participate.

The initial sample consisted of 286 adolescents examined in 2009, representative of the 12-year-old population at public and private schools in Juiz de Fora, state of Minas Gerais, Brazil. The sample size was calculated by the clustering technique. A previous study developed by the authors presented both the sample size calculation and the inclusion and exclusion criteria used at baseline in greater detail..$^{13}$ Briefly, we included all 12-year-old schoolchildren whose parents had consented their participation in the study and we excluded those with previous or current history of orthodontic treatment. After 3 years, the adolescents were contacted again to participate in the research.

\section{OHRQoL estimation}

OHRQoL was the dependent variable and it was estimated by the Child Perceptions Questionnaire $\mathrm{CPQ}_{11-14}{ }^{22}$ Locker $^{23}$ introduced different methods for assessing self-perceived oral health, such as OHRQoL, claiming that the differences between baseline and follow-up scores can be used as the dependent variable in analyses aimed at identifying predictors of change, such as socioenvironmental aspects and personal characteristics of participants at baseline.

The $\mathrm{CPQ}_{11-14}$ questionnaire was translated into Portuguese and validated for the Brazilian population by Barbosa et al., ${ }^{24}$ and demonstrated to have good psychometric properties. It consists of 37 questions divided into four domains: oral symptoms, functional limitations, emotional well-being, and social well-being. The answers to the questions are presented on a Likert scale ("Never" = 0; "Once or twice" = 1; "Sometimes" = 2; "Often"= 3; and "Very often" = 4), in which higher scores represent worse OHRQoL.

For the sake of data analysis during the follow-up period (2012), OHRQoL was categorized as "no improvement" and "improvement," as proposed by Locker et al. ${ }^{25}$ The total $\mathrm{CPQ}_{11-14}$ score was calculated by subtraction: "baseline score - follow-up score," and thus negative or zero results (no improvement = deterioration or maintenance), and positive results (improvement) were obtained.

The independent variables were obtained at baseline by application of a questionnaire and from the clinical evaluation conducted in 2009. The independent variables (clinical, socioenvironmental, and OHRQoLinformation) were selected based on previous cross-sectional studies on the topic. ${ }^{10,11,13,20}$ A questionnaire containing questions about education (fewer or more than 4 years of schooling) and home ownership (yes or no) was answered by the parents. The questionnaire administered to the adolescents contained questions about gender (male 
or female), number of siblings (none or more than one), and their perception of their oral health (excellent/very good/good or poor/very poor).

The adolescents were clinically assessed by two calibrated investigators (intra-examiner kappa greater than 0.91), based on World Health Organization criteria. ${ }^{26}$ The presence of bleeding and the number of decayed, missing, and filled teeth (DMFT index) were evaluated under natural light in the school environment. Another evaluator assessed malocclusion based on the DAI index (Dental Aesthetic Index), in which the total score obtained was dichotomized into with and without orthodontic treatment need, $<31$ and $\geq 31$, respectively, according to the criteria described by Estioko et al. ${ }^{27}$

\section{Data analysis}

Descriptive statistics was used and the proportions of the sample characteristics at baseline and in the follow-up period were compared using McNemar's test (significance level of 5\%). The independent variables were individually assessed to estimate the crude effects of dental care on change in OHRQoL and to find potential confounders.

Logistic regression is a statistical technique that aims to produce a model from a set of observations, which allows the prediction of values taken by a categorical variable, often binary, from a number of independent, explanatory, discrete and/or continuous variables. More details on the logistic regression model can be obtained in the study of Hosmer and Stanley. ${ }^{28}$

Logistic regression models, with explanatory variables assessed individually and jointly, were used to determine which clinical and socioenvironmental variables affected OHRQoL. The analyses were performed with the Statistical Analysis System (SAS) software program, using the logistic procedure, and the stepwise method of variable selection was used for conjoint analysis. The level of significance was set at 0.05 .

\section{Results}

The final sample included 170 (59.4\%) adolescents and loss to follow-up was mainly because many of them had changed schools (32 participants $11.2 \%)$, had moved away (24 participants $-8.4 \%$ ), or dropped out of the study (60 participants $-21 \%$ ).
Of the total number of adolescents followed up until 2012, 92 (54.1\%) were female and 78 (45.9\%) were male.

With regard to clinical conditions, the DMFT index increased from 1.01 (Standard deviation: 1.69) in 2009 to 1.66 (Standard deviation: 2.19) in 2012, accounting for a $64.3 \%$ increase in the mean value of decayed, missing, and filled teeth. According to the DAI index, 131 adolescents did not need orthodontic treatment in $2012(77.1 \%)$ compared to $161(94.7 \%)$ in 2009.

Table 1 shows the descriptive statistics. All the proportions of responses (socioenvironmental characteristics and clinical data) differed statistically between the baseline and follow-up periods. A posteriori power analysis was conducted to verify the power of the tests presented in Table 1 using the $G^{*}$ Power software. It was verified that the three lowest powers of the test, given by 1-error type II, were 57,64 and $72 \%$ for the covariates DMFT, children's perception of their oral health and home ownership, respectively. For all other covariates, the power of the tests obtained was greater than $98 \%$.

The results for the individual independent variables are presented in Table 2, which shows statistically significant associations of caries experience (DMFT) with changes in OHRQoL.

Table 3 presents the final results of the logistic regression. Only the DMFT index partly explained the variability in response to OHRQoL (by the change in $\mathrm{CPQ}_{11-14}$ scores). The results considered only the variable selected by the stepwise method and, thus, the probability of adolescents showing improvement in OHRQoL was expressed by the formula:

$$
\hat{\mathrm{p}}=\frac{\exp \left(-0.2151+0.7920^{*} \mathrm{DMFT}\right)}{1+\exp \left(-0.2151+0.7920^{*} \mathrm{DMFT}\right)}
$$

Therefore, the mean response adjusted for DMFT $>0$ (individuals with caries experience in 2009) is given by 0.4464 , i.e., the probability $(44.64 \%$ ) for an individual of this group to improve his/her OHRQoL. Considering $\mathrm{DMFT}=0$, i.e., an individual that was caries-free in 2009, the probability of improvement in OHRQoL increases to 0.6403 (64.03\%).

The odds ratio was obtained by $\mathrm{OR}=\exp (0.7920)$ $=2.21$, which means that the chance of an individual who was caries-free in 2009 to improve their OHRQoL is 2.21 times more than individuals with caries experience (DMFT >0) in 2009. 
Longitudinal impact of clinical and socioenvironmental variables on oral health-related quality of life in adolescents

Table 1. Descriptive data of the sample followed $(n=170)$ and comparison between proportions of clinical characteristics, socio-environmental and perceptions of parents in moments Baseline and Follow-up.

\begin{tabular}{|c|c|c|c|c|c|}
\hline \multirow{2}{*}{ Variable } & \multicolumn{2}{|c|}{2009} & \multicolumn{2}{|c|}{2012} & \multirow{2}{*}{$\mathrm{p}$-value } \\
\hline & $n$ & $\%$ & $\mathrm{n}$ & $\%$ & \\
\hline \multicolumn{6}{|l|}{ D of DMFT } \\
\hline$>0$ & 29 & 17.1 & 34 & 20.0 & \\
\hline$=0$ (without caries) & 141 & 82.9 & 136 & 80.0 & $<0.0001$ \\
\hline Total & 170 & 100.0 & 170 & 100.0 & \\
\hline \multicolumn{6}{|l|}{ DMFT } \\
\hline$>0$ & 56 & 32.9 & 77 & 45.3 & \\
\hline$=0$ (without caries experience) & 114 & 67.1 & 93 & 54.7 & 0.0092 \\
\hline Total & 170 & 100.0 & 170 & 100.0 & \\
\hline \multicolumn{6}{|l|}{ Bleeding } \\
\hline Yes & 21 & 12.4 & 34 & 20.0 & \\
\hline No & 149 & 87.6 & 136 & 80.0 & $<0.0001$ \\
\hline Total & 170 & 100.0 & 170 & 100.0 & \\
\hline \multicolumn{6}{|l|}{ Orthodontic treatment need } \\
\hline Yes & 39 & 22.9 & 9 & 5.3 & \\
\hline No & 131 & 77.1 & 161 & 94.7 & $<0.0001$ \\
\hline Total & 170 & 100.0 & 170 & 100.0 & \\
\hline \multicolumn{6}{|l|}{ Father's Education } \\
\hline$\leq 4$ years & 48 & 28.2 & 38 & 25.2 & \\
\hline$>4$ years & 122 & 71.8 & 113 & 74.8 & $<0.0001$ \\
\hline Total & 170 & 100.0 & $151^{*}$ & 100 & \\
\hline \multicolumn{6}{|l|}{ Mother's Education } \\
\hline$\leq 4$ years & 56 & 32.9 & 48 & 31.0 & \\
\hline$>4$ years & 114 & 67.1 & 107 & 69.0 & $<0.0001$ \\
\hline Total & 170 & 100.0 & $155^{* *}$ & 100.0 & \\
\hline \multicolumn{6}{|l|}{ Home ownership } \\
\hline No & 7 & 45.3 & 58 & 37.0 & \\
\hline Yes & 93 & 54.7 & 98 & 63.0 & 0.0057 \\
\hline Total & 170 & 100.0 & $156^{* * *}$ & 100.0 & \\
\hline \multicolumn{6}{|l|}{ Number of siblings } \\
\hline None & 19 & 11.2 & 10 & 5.9 & \\
\hline 1 or more & 151 & 88.8 & 160 & 94.1 & $<0.0001$ \\
\hline Total & 170 & 100.0 & 170 & 100.0 & \\
\hline \multicolumn{6}{|c|}{ Children's perception of their oral health } \\
\hline Fair/Poor & 63 & 37.1 & 67 & 39.4 & \\
\hline Excellent/very good/good & 107 & 62.9 & 103 & 60.6 & 0.0031 \\
\hline Total & 170 & 100.0 & 170 & 100.0 & \\
\hline
\end{tabular}

*19 not informed at follow-up; ${ }^{* *} 15$ not informed at follow-up; ${ }^{* * *} 14$ not informed at follow-up 
Table 2. Relationship between putative confounders/effect modifiers and "no improvement" and "improvement" changes in $C P Q_{11-14}$ along time.

\begin{tabular}{|c|c|c|c|c|c|c|c|}
\hline \multirow{3}{*}{ Variables } & \multirow{3}{*}{ Total } & \multicolumn{6}{|c|}{ Oral health related-quality of life } \\
\hline & & \multicolumn{2}{|c|}{ No improvement } & \multicolumn{2}{|c|}{ Improvement } & \multirow{2}{*}{ OR bruto } & \multirow{2}{*}{$95 \% \mathrm{Cl}$} \\
\hline & & $\mathrm{n}$ & $\%$ & $\mathrm{n}$ & $\%$ & & \\
\hline
\end{tabular}

\section{Gender}

$\begin{array}{llllll}\text { Boy } & 92 & 41 & 44.6 \% & 51 & 55.4 \% \\ \text { Girl } & 78 & 31 & 39.7 \% & 47 & 60.3 \%\end{array}$

Father's education

$\begin{array}{lccccc}\leq 4 \text { years } & 48 & 21 & 43.8 \% & 27 & 56.3 \% \\ >4 \text { years } & 122 & 51 & 41.8 \% & 71 & 58.2 \%\end{array}$

Mother's education

$\begin{array}{lccccc}\leq 4 \text { years } & 56 & 27 & 48.2 \% & 29 & 51.8 \% \\ >4 \text { years } & 114 & 45 & 39.5 \% & 69 & 60.5 \%\end{array}$

Home ownership

$\begin{array}{llllllll}\text { No } & 77 & 32 & 41.6 \% & 45 & 58.4 \% & 0.942 & 0.511-1.737 \\ \text { Yes } & 93 & 40 & 43.0 \% & 53 & 57.0 \% & \end{array}$

Number of siblings

$\begin{array}{lccccc}\text { None } & 19 & 9 & 47.4 \% & 10 & 52.6 \% \\ 1 \text { or more } & 151 & 63 & 41.7 \% & 88 & 58.3 \%\end{array}$

1.257

$0.483-3.273$

Children's perception of their oral health

$\begin{array}{lccccc}\text { Fair/Poor } & 63 & 26 & 41.3 \% & 37 & 58.7 \% \\ \text { Excellent/very good/good } & 107 & 46 & 43.0 \% & 61 & 57.0 \%\end{array}$

Orthodontic treatment need

$\begin{array}{lrrrrr}\text { Yes } & 39 & 14 & 35.9 \% & 25 & 64.1 \% \\ \text { No } & 131 & 58 & 44.3 \% & 73 & 55.7 \%\end{array}$

Bleeding

$\begin{array}{llllll}\text { Yes } & 21 & 9 & 42.9 \% & 12 & 57.1 \% \\ \text { No } & 149 & 63 & 42.3 \% & 86 & 57.7 \%\end{array}$

D of DMFT

$>0$

$\begin{array}{lllll}29 & 14 & 48.3 \% & 15 & 51.7 \%\end{array}$

$=0$ (without caries)

$141 \quad 58$

$41.1 \%$

$83 \quad 58.9 \%$

1.336

$0.599-2.978$

DMFT

$\begin{array}{llllllll}>0 & 56 & 31 & 55.4 \% & 25 & 44.6 \% & 2.208 & 1.151-4.234 \\ =0 \text { (without caries experience) } & 114 & 41 & 36.0 \% & 73 & 64.0 \% & & \end{array}$

OR: odds ratio; $\mathrm{Cl}$ : confidence interval 
Table 3. Logistic regression model with predictor of improvement in oral health related-quality of life after three years.

\begin{tabular}{lcccc}
\hline Variable & Estimate & $\begin{array}{c}\text { Standard } \\
\text { Error }\end{array}$ & Chi-square & p-value \\
\hline Intercept & -0.2151 & 0.2688 & 0.6404 & 0.4236 \\
DMFT & 0.7920 & 0.3322 & 56.843 & 0.0171 \\
\hline
\end{tabular}

\section{Discussion}

The present study demonstrated that absence of caries experience $(\mathrm{DMFT}=0)$ was a single important predictor for improvement of OHRQoL along time. To our knowledge, this is the first study in Brazil that has used a longitudinal observational design covering a 3-year period and using the $\mathrm{CPQ}_{11-14}$ questionnaire to evaluate changes in adolescents' OHRQoL. Moreover, this study brings new and important information about the variables that maintain their power to influence the OHRQoL of adolescents over time.

Published longitudinal studies on OHRQoL have generally focused on changes in their scores due to the consequences of and benefits from therapeutic interventions, for example, after orthodontic dental treatments ${ }^{29}$ periodontal treatment; ${ }^{30}$ early childhood caries, according to the perceptions of parents; ${ }^{31}$ atraumatic restorative treatment; ${ }^{32}$ educational preventive programme ${ }^{33}$ or dental caries treatment. ${ }^{34}$ However, studies evaluating the follow-up of the natural process of change in adolescents' perceptions of their OHRQoL over time is rarely found in the literature. A similar observational study was found only in Foster Page and Thomson. ${ }^{20}$

According to our results, caries experience at baseline was a predictor of changes in the OHRQoL of adolescents who remained in the final model. However, the same trend was not observed by Foster Page and Thomson, ${ }^{20}$ who found no associations between caries experience at baseline and changes in OHRQoL. Nevertheless, direct comparison of a study conducted in Brazil and another one performed in New Zealand must be made with reservation, since these are very different social, environmental, and cultural conditions among populations and distinct clinical profiles, which could have great influence on OHRQoL over time. ${ }^{12}$
Considering the numerous psychosocial changes over 3 years that may interfere in the clinical condition, adolescents' cognitive development and perception of quality of life may be mediated by broader contextual factors. ${ }^{19,35}$ Therefore, it is important for health professionals to know how these chains of risk will cumulatively tend to affect the clinical and psychosocial development of adolescents so that continuous interventions can be planned over their life course to address broader determinants of health. ${ }^{36}$

Moreover, research has shown that there are other psychosocial aspects, such as self-esteem, social capital, and sense of coherence associated with behaviors and oral clinical changes. ${ }^{19,21,37,38}$ Thus, although these variables were not evaluated herein, they may play a mediating role between caries experience (DMFT index) and changes in OHRQoL over time, as observed in the present study.

More than two decades ago researchers emphasized the importance of incorporating socioeconomic variables into longitudinal assessments of $\mathrm{OHRQ} \mathrm{L}$, as these variables influence the construction of subjective perception of OHRQoL. ${ }^{1}$ For this purpose, the present study included these variables in the regression model in order to determine their strength as predictors of improvement in OHRQoL. It is interesting to note that although cross-sectional studies have found associations between socioenvironmental conditions and OHRQoL, 9,10,11,12,13,14 the present study, with a longitudinal design, found that only the caries experience at baseline remained as a predictor of OHRQoL after 3 years, and highlighted the strong impact of clinical conditions on OHRQoL over time. This underscores the importance of a sociodental approach, with normative and subjective variables, by health professionals in order to evaluate and implement oral health actions for adolescents. ${ }^{2,9,39}$

Although malocclusion was a clinical variable included in the regression, it was not found to be a predictor of changes in OHRQoL after 3 years. In our view, this may have occurred because the number of adolescents who had orthodontic treatment needs, according to assessments at baseline and at follow-up, was much lower than those requiring treatment for dental caries. Unlike observational studies, clinical studies with post-orthodontic treatment assessments ${ }^{29}$ 
show divergent results from those of this study, because they concluded that aspects of malocclusion affected OHRQoL. However, this comparison between studies with different designs should be made with caution, since dental care intervention may determine much clearer and relatively expected changes in OHRQoL, as opposed to observational evaluation without any interference by the researcher.

From the perspective of the salutogenic model,$^{40}$ in which the focus was on protection factors for specific illness or disease, we found that adolescents who were completely caries-free at baseline (DMFT equal to zero) were more likely to improve their OHRQoL from ages 12 to 15 years than their counterparts (with caries experience). This finding makes us reflect about the importance of conducting preventive and health-promoting actions with adolescents, since it is known that this age group is more vulnerable to the presence of caries. ${ }^{20}$ Furthermore, aspects related to the sense of coherence and to general resistance resources, which indicate that peoples' life orientation may affect health, should be used in

\section{References}

1. Wilson IB, Cleary PD. Linking clinical variables with health-related quality of life: a conceptual model of patient outcomes. JAMA.1995;273(1):59-65. https://doi.org/10.1001/jama.1995.03520250075037

2. Locker D, Jokovic A, Tompson B, Prakash P. Is the Child Perceptions Questionnaire for 11-14 year olds sensitive to clinical and self-perceived variations in orthodontic status? Community Dent Oral Epidemiol. https://doi.org/10.1111 /j.1600-0528.2006.00324.x2007;35(3):179-85.

3. Barbosa TS, Gavião MB. Oral health-related quality of life in children: part II. Effects of clinical oral health status. A systematic review. Int J Dent Hyg. 2008;6(2):100-7. https://doi.org/10.1111/j.1601-5037.2008.00293.x

4. Biazevic MGH, Rissotto RR, Michel-Crosato E,

Mendes LA, Mendes MOA. Relationship between oral health and its impact on quality of life among adolescents. Braz Oral Res. 2008;22(1):36-42. https://doi.org/10.1590/S1806-83242008000100007

5. Dimberg L, Arnrup K, Bondemark L. The impact of malocclusion on the quality of life among children and adolescents: a systematic review of quantitative studies. Eur J Orthod. 2015;37(3):238-47. https://doi.org/10.1093/ejo/cju046 the planning of health-promoting interventions for this age group in order to promote improvements in their OHRQoL. ${ }^{38}$

The results of this study should be evaluated with caution since the overall $\mathrm{CPQ}_{11-14}$, rather than the domain scores, was used as the dependent variable, which ended up being a limitation of this study. The sample should be considered to have a small prevalence of clinical conditions. Also, loss to follow-up should be evaluated carefully because of the difficulty in gathering participants again after 3 years.

\section{Conclusion}

Caries experience was a predictor of OHRQoL in adolescents followed up for 3 years.

\section{Acknowledgments}

This study was supported by São Paulo Research Foundation - Fapesp (2011/17669-5 and 2011/01281-8), São Paulo, Brazil.
6. Locker D, Allen F. What do measures of 'oral health-related quality of life' measure?. Community Dent Oral Epidemiol. 2007;35(6):401-11. https://doi.org/10.1111/j.1600-0528.2007.00418.x

7. Engelmann JL, Tomazoni F, Oliveira MD, Ardenghi TM. Association between dental caries and socioeconomic factors in schoolchildren: a multilevel analysis. Braz Dent J. 2016;27(1):72-8. https://doi.org/10.1590/0103-6440201600435

8. Martins MT, Sardenberg F, Vale MP, Paiva SM, Pordeus IA. Dental caries and social factors: impact on quality of life in Brazilian children. Braz Oral Res. 2015;29(1):1-7. https://doi.org/10.1590/1807-3107BOR-2015.vol29.0133

9. Locker D. Disparities in oral health-related quality of life in a population of Canadian children. Community Dent Oral Epidemiol. 2007;35(5):348-56. https://doi.org/10.1111/j.1600-0528.2006.00323.x

10. Piovesan C, Antunes JLF, Guedes RS, Ardenghi TM. Impact of socioeconomic and clinical factors on child oral health-related quality of life (COHRQoL). Qual Life Res. 2010;19(9):1359-66. https://doi.org/10.1007/s11136-010-9692-7 
Longitudinal impact of clinical and socioenvironmental variables on oral health-related quality of life in adolescents

11. Paula JS, Leite ICG, Almeida AB, Ambrosano GMB, Pereira AC, Mialhe FL. The influence of oral health conditions, socioeconomic status and home environment factors on schoolchildren's self-perception of quality of life. Health Qual Life Outcomes. 2012;10:6. https://doi.org/10.1186/1477-7525-10-6

12. Kumar S, Kroon J, Lalloo R. A systematic review of the impact of parental socio-economic status and home environment characteristics on children's oral health related quality of life. Health Qual Life Outcomes. 2014;12(1):41. https://doi.org/10.1186/1477-7525-12-41

13. Paula JS, Leite IC, Almeida AB, Ambrosano GM, Mialhe FL. The impact of socioenvironmental characteristics on domains of oral health-related quality of life in Brazilian schoolchildren. BMC Oral Health. 2013;13(1):10. https://doi.org/10.1186/1472-6831-13-10

14. Aimée NR, van Wijk AJ, Maltz M, Varião MM, Mestrinho HD, Carvalho JC. Dental caries, fluorosis, oral health determinants, and quality of life in adolescents. Clin Oral Investig. 2017;21(5):1811-20.

15. Castilho AR, Mialhe FL, Barbosa TS, Puppin-Rontani RM. Influence of family environment on children's oral health: a systematic review. J Pediatr (Ri J). 2013;89(2):116-23. https://doi.org/10.1016/j.jped.2013.03.014

16. Levin KA, Currie C. Adolescent toothbrushing and the home environment: sociodemographic factors, family relationships and mealtime routines and disorganisation. Community Dent Oral Epidemiol. 2010;38(1):10-8. https://doi.org/10.1111/j.1600-0528.2009.00509.x

17. Polk DE, Weyant RJ, Manz MC. Socioeconomic factors in adolescents' oral health: are they mediated by oral hygiene behaviors or preventive interventions? Community Dent Oral Epidemiol. 2010;38(1):1-9. https://doi.org/10.1111/j.1600-0528.2009.00499.x

18. Bandayrel K, Johnston BC. Recent advances in patient and proxy-reported quality of life research. Health Qual Life Outcomes. Health Qual Life Outcomes. 2014;12(1):110. https://doi.org/10.1186/s12955-014-0110-7

19. Gururatana O, Baker SR, Robinson PG. Determinants of children's oral-health-related quality of life over time. Community Dent Oral Epidemiol. 2014;42(3):206-15. https://doi.org/10.1111/cdoe.12080

20. Foster Page LA, Thomson WM. Caries prevalence, severity, and 3-year increment, and their impact upon New Zealand adolescents' oral-health-related quality of life. J Public Health Dent. 2012;72(4):287-94. https://doi.org/10.1111/j.1752-7325.2012.00336.x

21. Benson PE, Da'as T, Johal A, Mandall NA, Williams AC, Baker SR et al. Relationships between dental appearance, self-esteem, socio-economic status, and oral healthrelated quality of life in UK schoolchildren: a 3 -year cohort study. Eur J Orthod. 2015t;37(5):481-90. https://doi.org/10.1093/ejo/cju076
22. Jokovic A, Locker D, Stephens M, Kenny D, Tompson B, Guyatt $G$. Validity and reliability of a measure of child oral health-related quality of life. J Dent Res. 2002;81(7):459-63. https://doi.org/10.1177/154405910208100705

23. Locker D. Issues in measuring change in selfperceived oral health status. Community Dent Oral Epidemiol. 1998;26(1):41-7. https://doi.org/10.1111/j.1600-0528.1998.tb02082.x

24. Barbosa TS, Tureli MC, Gavião MB. Validity and reliability of the Child Perceptions Questionnaires applied in Brazilian children. BMC Oral Health. 2009;9(1):13. https://doi.org/10.1186/1472-6831-9-13

25. Locker D, Jokovic A, Clarke M. Assessing the responsiveness of measures of oral health-related quality of life. Community Dent Oral Epidemiol 2004;32(1):10-8. https://doi.org/10.1111/j.1600-0528.2004.00114.x

26. World Health Organization. Oral health surveys: basic methods. 4th ed. Geneva: World Health Organization; 1997.

27. Estioko LJ, Wright FA, Morgan MV. Orthodontic treatment need of secondary schoolchildren in Heidelberg, Victoria: an epidemiologic study using the Dental Aesthetic Index. Community Dent Health. 1994;11(3):147-51.

28. Hosmer DW, Stanley L. Applied logistic regression. 2nd ed. New York: Wiley; 2000.

29. Zhou $Y$, Wang $Y$, Wang $X$, Volière $G, H u R$. The impact of orthodontic treatment on the quality of life a systematic review. BMC Oral Health. 2014;14(1):66. https://doi.org/10.1186/1472-6831-14-66

30. Öhrn K, Jönsson B. A comparison of two questionnaires measuring oral health-related quality of life before and after dental hygiene treatment in patients with periodontal disease. Int J Dent Hyg. 2012;10(1):9-14. https://doi.org/10.1111/j.1601-5037.2011.00511.x

31. Cunnion DT, Spiro A 3rd, Jones JA, Rich SE, Papageorgiou CP, Tate A et al. Pediatric oral health-related quality of life improvement after treatment of early childhood caries: a prospective multisite study. J Dent Child (Chic). 2010;77(1):4-11.

32. Mashoto KO, Astrøm AN, Skeie MS, Masalu JR. Changes in the quality of life of Tanzanian school children after treatment interventions using the Child-OIDP. Eur J Oral Sci. 2010;118(6):626-34. https://doi.org/10.1111/j.1600-0722.2010.00776.x

33. Amato JN, Barbosa TS, Kobayashi FY, Gavião MB. Changes in the oral-health-related quality of life of Brazilian children after an educational preventive programme: an 1-month longitudinal evaluation. Int J Dent Hyg. 2014;12(3):226-33. https://doi.org/10.1111/idh.12075

34. Paula JS, Sarracini KLM, Meneghim MC, Pereira AC, Ortega EMM, Martins NS et al. Longitudinal evaluation of the impact of dental caries treatment on oral health-related quality of life among schoolchildren. Eur J Oral Sci. 2015;123(3):173-8. https://doi.org/10.1111/eos.12188 
35. Wallander JL, Schmitt M, Koot HM. Quality of life measurement in children and adolescents: issues, instruments, and applications. J Clin Psychol. 2001;57(4):571-85. https://doi.org/10.1002/jclp.1029

36. Lu HX, Wong MCM, Lo ECM, McGrath C. Trends in oral health from childhood to early adulthood: a life course approach. Community Dent Oral Epidemiol. 2011;39(4):352-60. https://doi.org/10.1111/j.1600-0528.2011.00611.x 37. Atal S, Cheng C. Socioeconomic health disparities revisited: coping flexibility enhances health-related quality of life for individuals low in socioeconomic status. Health Qual Life Outcomes. 2016;14(1):7.

https://doi.org/10.1186/s12955-016-0410-1

38. Eriksson M, Lindström B. Antonovsky's sense of coherence scale and its relation with quality of life: a systematic review. J Epidemiol Community Health. 2007;61(11):938-44. https://doi.org/10.1136/jech.2006.056028

39. Leão, A., Sheiham, A. The development of a socio-dental measure of dental impacts on daily living. Community Dent Health. 1996;13(1):22-6.

40. Antonovsky, A. The salutogenic model as a theory to guide health promotion. Health Promot Int. 1996;11(1):11-8.

https://doi.org/10.1093/heapro/11 